on psychiatric care (Sargeant, 1993), which were similar to those from the Schizophrenia Association of Great Britain recelved by O'Shea.

Communication between health professionals and relatives was poor and the relatives felt unsupported and isolated. They were often ignorant of the diagnosis initially and wanted more easy access to hospital beds, although good community management was preferred by relatives in my sample in contrast to the groups who replied to O'Shea. This difference may reflect difficulties in establishing community facilities before hospital beds are closed. Those relatives I interviewed wished to be involved with the professional multidisciplinary team. Although the relatives were often the primary carers, they were not always informed of decisions that affected them.

I agree that medical education needs to take account of the families from which patients come. I wonder whether this is better placed at the postgraduate level and in the continuing education arena than at undergraduate level where the syllabus is already large and expanding rapidly. If the carers are to be supported the professionals need to support. Medical students will then learn by example.

SARGEANT, R.J. (1993) Schizophrenia: the problems for the family. Psychiatric Bulletin. 17, 14-15.

RHONA J. SARGEANT, Uffculme Clinic, Queensbridge Road, Moseley, Birmingham B13 8QD

Sir: Sargeant was 'surprised' to read that the National Schizophrenia Fellowship UK did not reply to my correspondence. Unfortunately, that is not uncommon in this type of research (O'Shea, 1990). What was far more surprising was the fact that the most distant country involved in all three of my papers (New Zealand), of which the article on schizophrenia was the third, was consistently first in giving replies. The difference between Sargeant's and my own findings in relation to where one might wish to be treated may be more apparent than real and may depend on the manner in which questions are phrased: if your choice is confined to choosing between hospitals it is reasonably straightforward, whereas if you prefer to be treated extramurally but the perceived facilities are inadequate then some distress may be engendered.

Finally, psychiatry, at least until recently, was all too often seen as something which could be left to those who specialised in it after qualifying. How many doctors need to remember, or do remember, the amount of anatomy that, at least in my time, they were forced to digest in medical school? Surely the branches of some vessels and nerves could be diverted to make way for a consideration of the family. After all, general practice used to be known as family medicine!
O'SHEA, B. (1990) Huntington's disease association in Australia. Psychiatric Bulletin, 14, 94.

BRIAN O'ShEA, Newcastle Hospital, Greystones, County Wicklow, Ireland

\section{Training in research methods}

Sir: I was interested to read correspondence from Kidd, Stark \& Henderson (Psychiatric Bulletin, January 1994, 18, 55-56) about research by trainees, and the BJP Review of Books article 'Psychiatry's Research Toolbox' by Peter Jones, particularly his account of Freeman \& Tyrers' Research Methods in Psychiatry. A Beginner's Guide. I wish I had been aware of the existence of this book when embarking upon my own research project. I had excellent supervision, but there are things that nobody tells you, such as securing a parking space close to the door to spare the biceps brachil and attssimus dorst while carrying 2000 questionnaires to and from the printers, other departments and the post room. Probably the most important point in setting up a postal survey is ordering self-seal envelopes - this is obvious to those who have tried licking or sponging 2000 A4 envelopes. Warning about those excruciating cuts to the digits caused by edges of paper is warranted and the variant of lesions to the lips and tongue, caused by ignoring advice about envelopes.

Next time I will buy Research Methods in Psychiatry. A Beginner's Guide, go on a touch-typing course, keep triple-checked copies of my reference list in three separate buildings and become expert in the latest computer reference searching systems before I begin, and I will always be nice to librarians.

Training in research, and the availability of a good, basic textbook, it vital. The question noone dares to ask is "OK - yes - but how do you do it?". The mystique needs to be removed, so we all feel confident enough to start early, setting up small, well organised projects which can be slotted into a busy job. If we are to be in print by senior registrar interviews, with the lengthy submission processes, one needs to start at an SHO level.

Freeman, C. \& TYrer, P. (eds.) (1992) Research Methods in Psychiatry. A Beginner's Guide. London: Gaskell (Royal College of Psychiatrists).

JONEs. P. (1994) Psychlatry's research toolbox. BJP Review of Books, 7, 6-9.

Helen M. BIRChall, Leicester General Hospital, Letcester LE5 4PW

\section{Label of personality disorder}

Sir: I am currently preparing a paper on the politics of personality disorder. I came across $\mathrm{Dr}$ 
Steadman's letter (Psychiatric Bulletin, 1993, 17. 774). It is a perfect example of the problem I am writing about. It illustrates the use of a medical diagnosis for political purposes. Dr Steadman accurately describes a common situation, but without seeming to realise the significance of what he is saying. His vignette is tantamount to arguing that a patient who would otherwise be suitable for in-patient care should be deemed unsuitable and have his or her admission vetoed if the label of personality disorder has been applied to the patient in the past. What possible medical (or indeed moral) justification can there be for such discrimination? No wonder some psychiatrists are reluctant to write the powerful negative term 'personality disorder' in the patient's notes. This reluctance, which is not always present, is the only comfort I can draw from this depressing letter.

JOHN GuNN, Institute of Psychiatry, Denmark Hill, London SE5 8AF

Sir: Dr Steadman (Psychiatric Bulletin, 1993, 17, 774) wonders whether the 'diagnosis' of 'personality disorder' is being omitted, and speculates as to why. I would suggest that the main reason is that this term is at best unhelpful and at worst a medicalised term of abuse.

Freeman (1988) argues that it "tells you nothing about the patient, communicates nothing of certainty to a colleague and predicts little about the past, present or future of the individuals". Any maladaptive character traits should be described and, if there are enough to qualify as a specific syndrome, then that specific diagnosis should be used. Otherwise the term is as accurate as 'mood disorder'.

Saying someone has a 'personality disorder' would indicate that this person has annoyed you. A spurious medical label does not make it acceptable in medical records. Such derogatory labels stick and, as Freeman points out, make patients "less likely to receive adequate treatment, or is used as a reason for not offering treatment at all". This term deserves the same fate as earlier terms of psychiatric abuse like 'hysterical' or 'latent homosexual'.

Most of us would turn away angry drink patients from Casualty after a full assessment but I hope many would not let the term 'personality disorder' colour our management.

Freeman, C.P. (1988) Personality disorder. In Companion to Psychiatric Studies (4th edition) (eds. R.E. Kendell \& A.K. Zeally). Edinburgh: Churchill Livingstone, p. 407.

CARMElo Aguilina, Chase Farm Hospital, Enfield, Middlesex EN2 8JL

Sir: In response to 'Personality disorder, a declining diagnosis' (Psychiatric Bulletin, 1993, 17, 774), I also have noticed a decline in the diag- nosis of 'personality disorder' which used to be found so readily in psychiatric medical notes. In contrast to Dr Steadman, I am greatly relieved that this label has become less popular. The stigma of a diagnosis of personality disorder often precludes proper assessment of mental state and suicide risk and produces feelings of hostility to the patient by nursing and medical staff. Thank goodness for the Data Protection Act; we should not be making a diagnosis that cannot be discussed in an open manner with the patient.

FRANCES FOSTER, Merseyside Regional Registrar Rotation

Sir: Thank you for allowing me to respond to the correspondence (Professor Gunn, Dr Aquilina, and Dr Foster) regarding my letter 'Personality disorder, a declining diagnosis?' (Psychiatric Bulletin, 1993, 17, 774).

To expand on my original letter, the 'anger' described contained elements of psychotic symptomatology, which is why I had initially considered admission. These elements had been fully evaluated at the day hospital and had eventually been attributed to forming part of the personality disorder rather than as components of a psychotic illness.

I maintain that the category of personality disorder is an important one, and we should be concerned about its declining use. The quote from Freeman (1988) that "it tells you nothing about the patient" is surely an exaggeration?

Freeman, C.P. (1988) Personality disorder. In Companion to Psychiatric Studies (4th edition) (eds. R.E. Kendell \& A.K Zeally). Edinburgh: Churchill Livingstone. p 407.

PhILIP STEAdMan, Sutton Hospital, Sutton, Surrey SM2 5NF

Sir: I was surprised to read, in 'Personality disorder; a declining diagnosis? (Psychiatric Bulletin, 1993, 17, 774), that multidisciplinary colleagues tend to leave out 'personality disorder' as a diagnosis. This suggests a fear of incurring the wrath of that individual "in case he/she sees his / her notes".

My experience, has been along the same lines. As clinicians we need to look at where it exists and explore the reasons why. With the Data Protection Act, it seems that some health professionals are hesitant when it comes to a diagnosis. From speaking to senior nursing colleagues there appears to be a movement away from accepted psychiatric diagnoses, which seem viewed in some cases as derogatory labels. If so I wonder if we are moving to a time when, as members of a multidisciplinary team, we will be speaking in tongues in the absence of an interpreter.

PATRICK QUINN, St Andrew's Hospital (Southside), Yarmouth Road, Norwich NR7 OSS 